\title{
Needs and Preferences of Middle-Aged and Older Adults in Taiwan for Companion Robots and Pets: Survey Study
}

\author{
Ching-Ju Chiu*, PhD; Shiuan Hsieh", MS; Chia-Wei Li, MS \\ Institute of Gerontology, College of Medicine, National Cheng Kung University, Tainan, Taiwan \\ *these authors contributed equally
}

\section{Corresponding Author:}

Ching-Ju Chiu, PhD

Institute of Gerontology, College of Medicine

National Cheng Kung University

No. 1, University Road

Tainan, 70101

Taiwan

Phone: 88662353535 ext 5739

Fax: 88663028175

Email: cjchiu@mail.ncku.edu.tw

\section{Abstract}

Background: In recent years, robots have been considered a new tech industry that can be used to solve the shortage in human resources in the field of health care. Also, animal-assisted therapy has been used to provide assistance, companionship, and interaction among the elderly and has been shown to have a positive impact on their emotional and psychological well-being. Both pets and robots can provide dynamic communication and positive interaction patterns. However, preferences for middle-aged and older adults in this regard are not clear.

Objective: This study explored the degree of acceptance of robots and pets as partners in later life and to determine the needs and preferences of elderly individuals related to companion robots.

Methods: A total of 273 middle-aged and older adults aged $\geq 45$ years and living in the community were invited to answer a structured questionnaire after watching a companion robot video. Sociodemographic data, physical health status and activities, experience with technology, eHealth literacy, and acceptance and attitude toward robots and pets were recorded and analyzed using multinomial logistic regression analysis.

Results: Age, level of education, type of dwelling, occupation, retirement status, number of comorbidities, experience with pets, experience using apps, and eHealth literacy were significantly associated with acceptance of robots and pets. Middle-aged and older women preferred robots with an animal-like appearance, while men preferred robots that resembled a human adult. In terms of robot functions, participants preferred a companion robot with dancing, singing, storytelling, or news-reporting functions. Participants' marital status and whether or not they lived alone affected their preference of functions in the companion robot.

Conclusions: Findings from this study inform the development of social robots with regard to their appearance and functions to address loneliness in later life in fast-aging societies.

(J Med Internet Res 2021;23(6):e23471) doi: 10.2196/23471

\section{KEYWORDS}

middle-aged adults; older adults; companionship demand; robot; pet; acceptance

\section{Introduction}

Along with increases in the size of the aging population, the demands for care and medical and health care manpower for the elderly population are also increasing. Determining how to adapt to these changes, using limited resources to meet the needs of care recipients, and reducing the burden on caregivers so that middle-aged and older adults have a high quality of life in their old age is an important issue that cannot be ignored.

Cowan [1] divided the issues to be faced by an aging society into 8 categories: dependent living, fall risk, chronic disease, dementia, social isolation, depression, poor well-being, and poor medication management. However, an existing literature review pointed out that in order to establish relevant 
advanced-age health technologies designed to solve the issues mentioned above, the issues could be divided into 6 groups: general information and communications technology (ICT), robotics, telemedicine, sensor technology, medication management applications, and video games [1].

Over the past decade, the elderly population has been the demographic with the fastest growing use of technological products such as the internet and computers [2,3], and a growing number of studies have shown that health-related ICTs can effectively reduce medical expenditures and care costs and enhance the quality of life of middle-aged and older adults [4,5]. In addition, technological products can help middle-aged and older adults live independently at home and provide health care and medical services in remote areas through mobile health (mHealth) strategies [6]; among these technological products are robots that can assist humans in performing repetitive and dangerous work and become the additional manpower needed for health care [7].

A health care robot is a robot that monitors or promotes physical and mental health and mitigates social psychological problems in the elderly. According to their functions, these robots can be divided into 2 types: rehabilitation robots and social robots [8]. Rehabilitation robots are auxiliary devices that provide physical assistance and make it easier for users to perform physical tasks. They include such things as smart wheelchairs, artificial limbs, and exoskeletons. Social robots interact with the elderly, providing companionship or improving daily life. These robots can be further divided into service-type robots and companionship robots. The function of the service-type robot is mainly related to supporting the independent life of the elderly individual, such as assisting with eating, bathing, toileting, or dressing, as well as performing housework and providing health and safety monitoring. A companionship robot promotes the physical and mental health of elderly persons and enhances their quality of life through companionship, such as the robotic seal PARO that accompanies elderly individuals with dementia; the robot Huggable, which was specially developed for elderly care experimental research; and the robotic dog Aibo, which was intended to improve the quality of life of older individuals and disabled patients $[9,10]$. Studies have shown that older people prefer less human-looking robots $[11,12]$ and especially enjoy pet-like robots, which are widely used in the care of elderly persons with intellectual disabilities and provide pet-like companionship in lieu of real animals $[13,14]$. For example, the therapeutic robotic seal pet PARO, which was developed in Japan in 2004, has a body covered with more than 100 sensors and can interact with people. Survey results show that because PARO's appearance is unfamiliar to people, it is less likely that people will feel a sense of artificial interaction with an animal, and it is more likely to be accepted by the elderly [15]. Many studies have also shown that PARO can improve depression, increase social interaction, and positively stimulate cognitive functions in elderly persons with dementia [16,17], which suggests that robot-assisted therapy is a new therapeutic tool for use among the elderly [18-20]. According to the literature review [21], robot-assisted therapy is beneficial to the moods and behavior of elderly persons. A pet-like social robot can stimulate elderly persons to interact and talk with others and remind older adults of their past experiences with companion pets, while posing fewer concerns about safety (such as attacks or bites) and hygiene (allergies, infections, or dirt) that are associated with real pets. Older adults with dementia can also get the same emotional comfort from robot-assisted therapy as they would from their interaction with real pets. As a result, a pet-like robot provides not only simple entertainment but also assistance, companionship, therapy, interaction, and stimulation, as well as other functions and services [21].

However, technology may not be a substitute for human assistance, companionship, and interaction. A study was conducted to enable "robotic dog doctors" to accompany the elderly through animal-assisted therapy, and the results of the study showed that it had a positive effect on the mental and social health of the elderly participants. The study indicated that animal-assisted therapy can improve emotional and behavioral problems, as well as problems with aggression, in elderly individuals with dementia and can have a positive effect on the mental and social health of all elderly persons. Animal-assisted therapy is often recommended as a goal-oriented nonpharmaceutical therapy for mental problems [22]. For example, a study by Garrity et al [23] on widowed and socially isolated elderly persons over the past year found that those who had no experience with keeping pets were more depressed than those who had such experience. There are also studies showing that keeping pets is related to the survival rate of cardiovascular disease in the elderly [24], suggesting that pet companionship has a curative effect that cannot be ignored in clinical care and treatment. Some scholars have suggested that patients with dementia can experience a reduction in their degree of loneliness and engage in social interaction by interacting with robot pets and get pleasure and attention from it as well as spiritual comfort $[25,26]$. Thus, robot pets provide a new therapeutic option for the elderly with dementia. Furthermore, animal protection regulations in countries in addition to a lack of adequate animal training makes robot pets more attractive than animal pets. For example, people generally have doubts about the safety and health of animals in Taiwan, which leads to a lot of restrictions on their implementation in therapy [27]. Therefore, robots or robot pets provide the elderly with dynamic, 2-way communication and a positive interaction mode, which can be regarded as another option for them in later life. Robots can do more dangerous and tiring work in the home care of elderly persons, but they may undergo failure and present financial and ethical issues. Although pets have more spontaneous reactions and richer emotional responses and can provide more tactile stimulation, they present safety and health issues that must be taken into consideration, as well as extra time-consuming care requirements. The aforementioned factors affect the user's choice. According to the theory of planned behavior proposed by Ajzen [28], the occurrence of a behavior depends on the intensity of people's intentions, and the intensity of intentions is determined by 3 factors: attitude, subjective norms, and perceived behavioral control. Therefore, it is important to explore what factors affect the acceptance of robots and pets among middle-aged and older adults in Taiwan and to understand whether these factors correspond to the theory of planned behavior. 
Thodberg et al [29] performed a study that compared pets with robotic dogs. At the beginning of the study, the robotic pet PARO and real pets (dogs) had the same impact on residents. However, with increases in interaction time, residents decreased their conversation and eye contact with PARO, but their focus on and interaction with the dogs remained stable [29]. The study also found that the real animals had more spontaneous and richer emotional responses than the robotic pets and that subjects could get more active tactile stimulation. Compared with toy animals, both robotic pets and real animals can provide 2 -way dynamic communication, so it is feasible to use a robot/robot pet as a companion object and an auxiliary technological device for stimulating the sensory and cognitive functions of elderly individuals. However, most of the existing studies exploring the effectiveness of robot pet interventions in the elderly population (eg, psychological and behavioral effects and impact on quality of life) have been conducted on institutionalized elderly individuals with dementia for which long-term care was provided [30-33]; few of the studies have included elderly persons in the community as the study population. In particular, there has been a lack of study on the attitudes, degree of acceptance, and needs of middle-aged and older adults as they relate to robots. In the past, there have also been no studies comparing pets with robots in terms of their use as companion objects. This study is aimed toward closing these gaps in the existing literature to discuss the companion needs of middle-aged and older adults in Taiwan in order to understand their choices of robots or live pets as companion objects in later life and to further discuss the preferences of middle-aged and older adults for companionship robots, as well as other related factors.

\section{Methods}

\section{Participants}

Adults over age 45 years in Taiwan were invited to participate in this study using a convenience sampling method based on the sample selection standard. The number of participants needed for the study was determined as the number of variables $(n=26)$ multiplied by 10 . Thus, a total of 273 older adults living in the community comprised the sample. The questionnaire was distributed in gathering places for the elderly in Taiwan such as community universities, senior citizen learning centers, community care strongholds, day-care strongholds, and hospital clinics all over Taiwan. The inclusion criteria for participants were as follows: (1) able to communicate in Mandarin and Taiwanese; (2) willing to be interviewed by researchers, to fill out the questionnaire on their own, or to fill out an electronic questionnaire with a tablet computer; and (3) agreed to participate in the study and to sign a consent form. The exclusion conditions were as follows: (1) resided somewhere other than Taiwan, and (2) were suffering from moderate to severe cognitive impairment or unable to answer questions without coercion.

\section{Measures}

A structural questionnaire was used as the research tool. The content of the questionnaire included 4 parts: sociodemographic

data, physical and mental health status and activities, technology use and eHealth literacy, and robot and pet experience.

The sociodemographic data included age, gender, education level, marital status, number of children, place of residence, whether living alone or not, working status, economic status, self-rated health status, and number of chronic diseases.

The physical and mental health status and activities included social participation, leisure activities, social support, depression status, and personality traits. Among them, social participation and leisure activities were measured using the Ministry of Health and Welfare Taiwan Longitudinal Study on Aging questionnaire [34]. Social support was measured using the Inventory of Socially Supportive Behavior (ISSB [35,36]). This inventory consists of 10 questions relating to 4 types of social support: emotional support (3 questions), information support (2 questions), substantive support (2 questions), and social integration (3 questions). In the scoring system for the ISSB, a score of 1 represents unsatisfied, 2 represents neutral, and 3 represents satisfied; the higher the score, the higher the perceived social support. An overall internal consistency coefficient of .91 represents emotional support for each support type $\alpha$ reliability coefficient; a coefficient of .81 represents information support; a coefficient of .73 represents substantive support; and a coefficient of .81 represents social integration [37]. The depression status was measured using the simplified, 10-item version of the Center for Epidemiologic Studies Depression Scale (CES-D [38]), which was translated into Chinese. The CES-D comprises 10 positive and 10 negative questions that are scored on Likert scales ranging from 0 to 3, with the total score ranging from 0 to 30 and a total score of greater than 10 representing depression. The overall internal consistency Cronbach $\alpha$ value ranges from .78 to .87 [39]. The personality assessment was carried out using the International Personality Item Pool (IPIP) big 5 personality scale developed by Goldberg in 1992 [40], which was first translated into a simplified Chinese version [41] and then changed to a traditional Chinese version with customary modifiers used by the Taiwanese population [42]. A single factor was screened out from the original 50 questions, and the questions with higher factor loadings in each domain were developed into a new, 15 -item version of the IPIP (IPIP-15). This simplified version of the IPIP big 5 personality scale is divided into 5 dimensions - extroversion, friendliness, rigorousness, emotional stability, and intelligence/imagination - that are scored from 0 to 5 , where 1 =imprecise, $2=$ slightly imprecise, $3=$ ordinary, $4=$ slightly precise, and $5=$ very precise. The Cronbach $\alpha$ reliability coefficient judging the internal consistency of each scale ranged between .67 and .83 , and the factor loading ranged between .61 and .83 , indicating convergent validity. The correlation between the IPIP-15 and the personality scales corresponding to the original IPIP-50 ranged between .81 and .88 , which indicated that the convergent validity was acceptable [42].

Participants' experience in the use of technology, networking, and eHealth literacy were also assessed. The question about experience with the use of technology and networking was answered by subjects based on their past experience (ie, whether they had experience using the internet and downloading and 
using mobile apps). The question about eHealth literacy was assessed using the eHealth Literacy Scale (eHEALS), which is an 8-item measure that assesses the participant's internet use and search skills, ability to evaluate online content, and confidence in their internet-searching abilities. This scale is scored with 4 points, with the options being entirely disagree, disagree, agree, and strongly agree, which are scored 1, 2, 3, and 4 , respectively. The internal consistency Cronbach $\alpha$ reliability coefficient for each item is .88 , and the factor load ranges between .60 and $.84[43,44]$.

Experience with and acceptance of robots and pets included the acceptability of choosing a robot or pet as a companion object in later life, the type of companionship robot desired/favored, and past experience with keeping pets. Among these indices, the question about the acceptability of robots/pets was answered based on the response, "Acceptability of choosing a robot or pet as a companion object in later life." It was scored from 0 to 10 , with 0 representing completely unacceptable and 10 representing quite acceptable, and the higher the score, the higher the degree of acceptability. In addition, when the type of companion robots desired/favored was also evaluated, subjects were requested to choose the types and functions of the robots according to their preferences or needs. The choices included the companionship robot's services (eg, assisting with family tasks, health monitoring, safety monitoring), skills (eg, juggling, dancing, singing), interaction (eg, chatting, storytelling, news reporting, joke telling, providing child-like dialogue), expression, and appearance (eg, resembling an animal, human infant or adult, or nonbiological form), as well as other functions.

\section{Procedure}

The study was conducted between May and June 2018. A cross-sectional survey research method was used to survey the degree of acceptance and factors related to the choices made by middle-aged and older adults in Taiwan of a robot or pet as their companion object in later life. This study was approved by the institutional review board (IRB) of National Cheng Kung University Hospital in Taiwan (No. A-ER-105-509). The study collection methods and procedures are shown in Figure 1.

Figure 1. Research and data collection flowchart.

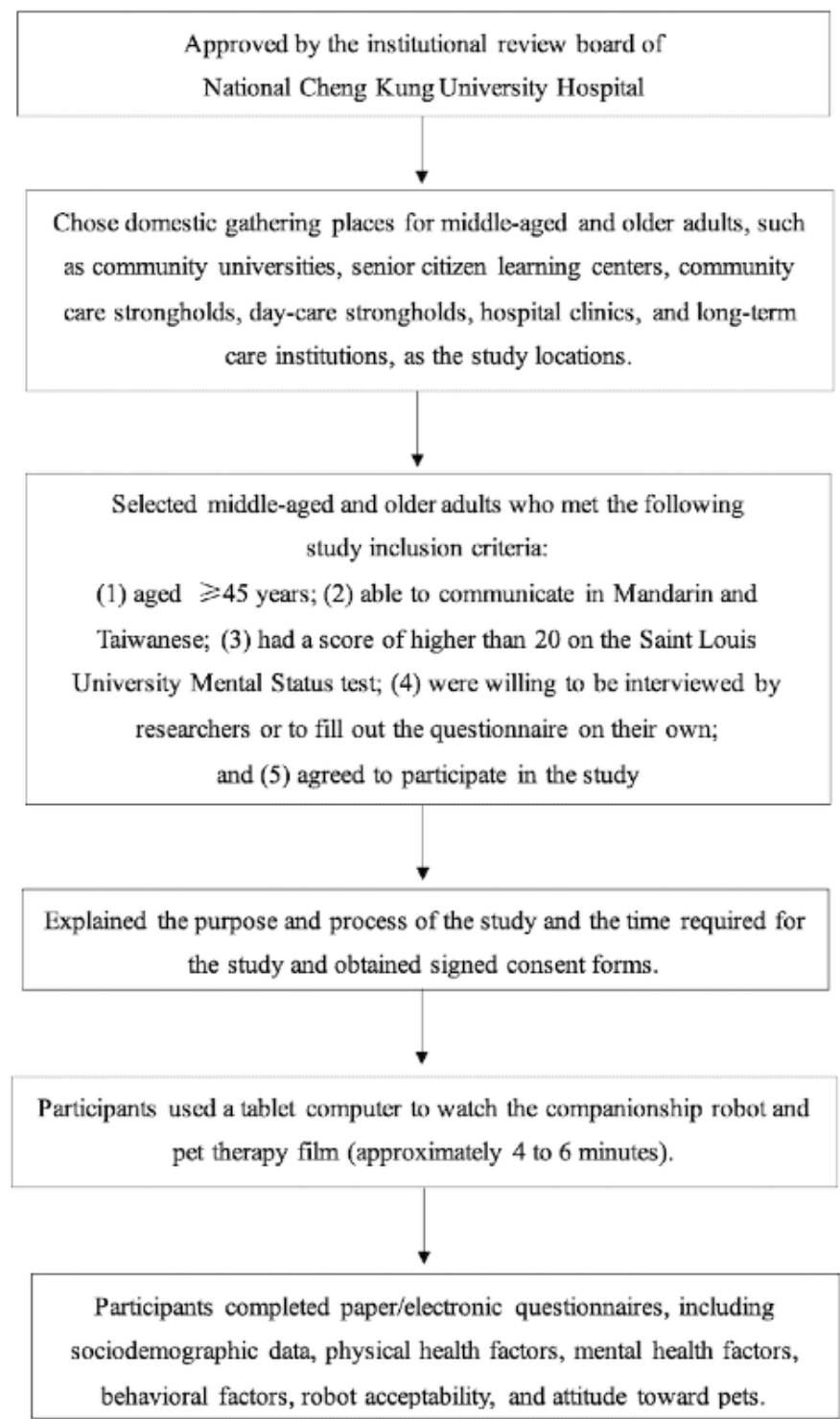


With the consent of the IRB of National Cheng Kung University Hospital in Taiwan, middle-aged and older adults in Taiwan were invited to participate in the study, and gathering places for the middle-aged and older adults, such as community universities, senior citizen learning centers, community care strongholds, and day-care strongholds, were chosen as places to distribute questionnaires. Middle-aged and older adults who met the following inclusion criteria were selected: (1) aged $\geq 45$ years, (2) able to communicate in Mandarin and Taiwanese, (3) had a Saint Louis University Mental Status test score higher than 20, (4) willing to be interviewed by the researchers or to fill out the questionnaire on their own, and (5) agreed to participate in the study and sign a consent form. The researchers explained to the subjects the study's purpose, process, and duration. After signing the consent form, the subjects used a tablet computer to watch a companionship robot film, after which they completed a questionnaire.

A companionship robot film was used in the study to provide a brief introduction to each type of companionship robot and was explained by the researchers at the time it was played. The film included robots with various physical characteristics (Multimedia Appendix 1), such as resembling an adult, an infant, an animal, or a nonbiological object, and presented the different functions of each robot, such as assisting with family tasks, health monitoring, safety monitoring, and other services, and the content of the robots' interactions with users, such as chatting, reporting news, reporting weather, singing, dancing, and making various expressions, among other functions.

\section{Statistics}

The descriptive statistics included an analysis of the sociodemographic variables, physical health factors, past experience with keeping pets, and experience in the use of technology as they related to variables such as the acceptability of choosing a robot or pet as a companion object in later life using a $t$ test and a 1-way analysis of variance. Differences among the sociodemographic variables, physical health factors, past experience with keeping pets, and experience with the use of technology, as well as other variables related to the elderly, were verified using the chi-square test among 4 groups of robot/pet preferences. The analysis of the correlation between the continuous variables was related to the Pearson correlation and included age, number of years living alone, IPIP-15 score, CES-D score, ISSB score, eHEALS score, and the level of acceptance of a robot or pet as a companion object in later life. A multiple regression analysis was used to analyze the between-variable correlations, such as gender, age, education level, living alone or not, retirement status, number of comorbidities, ISSB score, eHEALS score, IPIP-15 score, and acceptance of either robots or pets. Finally, a multinomial logistic regression analysis was used to analyze the predictive power of different groups of robot or pet acceptability in the middle-aged and older adults based on the following variables: (1) both robots and pets were highly acceptable (HH), (2) preferred choice was a robot (HL), (3) preferred choice was a pet (LH), and (4) neither robots nor pets were acceptable (LL).

\section{Results}

\section{Descriptive Analysis of the Subjects' Basic Data}

For the purpose of discussing the degree to which the middle-aged and older adults preferred a robot or pet as their companion object in later life in Taiwan, the questionnaires were distributed at 6 community care strongholds, 5 community centers, and 3 large-scale activities related to respecting the elderly and Mother's Day events in the north, middle, and southern parts of Taiwan. A total of 273 subjects who met the inclusion criteria were selected out of 300 middle-aged and older adults living in the community who were aged $\geq 45$ years, and a total of 240 valid questionnaires were obtained after those with missing data or incorrect answers $(n=33)$ were removed. The minimum and maximum ages of the participants were 45 years and 94 years, respectively. The average age was 60.68 years, and there were $172(71.7 \%)$ female participants and 68 (28.3\%) male participants. The majority of participants were highly educated $(183 / 240,76.2 \%)$, had a partner $(170 / 240$, $70.8 \%)$, lived in the city $(214 / 240,89.2 \%)$, did not live alone $(215 / 240,89.6 \%)$, lived with children $(221 / 240,92.1 \%)$, had no experience with using robots $(197 / 240,82.1 \%)$, had experience using the internet $(196 / 240,81.7 \%)$, could download and use an app $(184 / 240,76.7 \%)$, had experience with keeping pets $(152 / 240,63.6 \%)$, and had no experience with animal-assisted therapy $(226 / 240,94.2 \%)$. The subjects reported an average of 0.65 chronic conditions and an average self-reported health score of 3.53 (out of 5). On average, subjects' level of acceptance of robots and pets was 5.69 points and 4.72 points, respectively. A detailed chart of the data distribution is shown in Table 1. 
Table 1. Basic sociodemographic data of participants.

\begin{tabular}{|c|c|c|c|c|c|c|}
\hline \multirow[t]{2}{*}{ Characteristic } & \multirow[b]{2}{*}{$\begin{array}{l}\text { Full sample } \\
(\mathrm{N}=240)\end{array}$} & \multicolumn{3}{|c|}{ Preference of robot or pet as a companion } & \multirow[b]{2}{*}{$\begin{array}{l}\text { Neither is accept- } \\
\text { able }(n=61,25.4 \%)\end{array}$} & \multirow[b]{2}{*}{$\begin{array}{l}\text { Verification } \\
\text { value }\left(F / \chi^{2}\right)\end{array}$} \\
\hline & & $\begin{array}{l}\text { Both are highly } \\
\text { acceptable }^{\mathrm{a}} \\
(\mathrm{n}=81,33.8 \%)\end{array}$ & $\begin{array}{l}\text { Prefer robot } \\
(n=42,17.5 \%)\end{array}$ & $\begin{array}{l}\text { Prefer pet } \\
(\mathrm{n}=56,23.3 \%)\end{array}$ & & \\
\hline Age (years), mean (SD) & $60.68(10.496)$ & & & & & 13.65 \\
\hline $45-54$ & $85(35.4)$ & $37(45.7)$ & $8(19.0)$ & $22(39.3)$ & $18(29.5)$ & \\
\hline $55-64$ & $73(30.4)$ & $21(25.9)$ & $13(31.0)$ & $20(35.7)$ & $19(31.1)$ & \\
\hline $65-74$ & $53(22.1)$ & $14(17.7)$ & $14(33.3)$ & $10(17.9)$ & $15(24.6)$ & \\
\hline$\geq 75$ & $29(12.1)$ & $9(11.1)$ & $7(16.7)$ & $4(7.1)$ & $9(14.8)$ & \\
\hline Gender, n (\%) & & & & & & 1.34 \\
\hline Male & $68(28.3)$ & $22(27.2)$ & $12(28.6)$ & $19(33.9)$ & $15(24.6)$ & \\
\hline Education level, n (\%) & & & & & & 9.41 \\
\hline Below primary school & $57(23.8)$ & $15(18.5)$ & $15(35.7)$ & $11(19.6)$ & $16(26.2)$ & \\
\hline $\begin{array}{l}\text { Secondary school/senior high school } \\
\text { (higher vocational school) }\end{array}$ & $73(30.4)$ & $23(28.4)$ & $8(19.0)$ & $19(33.9)$ & $23(37.7)$ & \\
\hline University and above & $110(45.8)$ & $43(53.1)$ & $19(45.2)$ & $26(46.4)$ & $22(36.1)$ & \\
\hline Marital status, n (\%) & & & & & & 4.48 \\
\hline Unmarried/widowed/no partner & $70(29.2)$ & $18(22.2)$ & $16(38.1)$ & $15(26.8)$ & $21(34.4)$ & \\
\hline Married or has a partner & $170(70.8)$ & $63(77.8)$ & $26(61.9)$ & $41(73.2)$ & $40(65.6)$ & \\
\hline Residence, n (\%) & & & & & & $0.866^{\mathrm{b}}$ \\
\hline City & $214(89.2)$ & $71(33.2)$ & $38(90.5)$ & $49(87.5)$ & $56(91.8)$ & \\
\hline Type of dwelling, n (\%) & & & & & & 10.19 \\
\hline House & $109(45.4)$ & $42(51.9)$ & $20(47.6)$ & $23(41.1)$ & $24(39.3)$ & \\
\hline Apartment building without elevator & $39(16.3)$ & $13(16.0)$ & $4(9.5)$ & $6(10.7)$ & $16(26.2)$ & \\
\hline Apartment building with elevator & $92(38.3)$ & $26(32.1)$ & $18(42.9)$ & $27(48.2)$ & $21(34.4)$ & \\
\hline Lives alone, n (\%) & & & & & & $4.244^{\mathrm{b}}$ \\
\hline Yes & $25(10.4)$ & $7(8.6)$ & $5(11.9)$ & $3(5.4)$ & $10(16.4)$ & \\
\hline No & $215(89.6)$ & $74(91.4)$ & $37(88.1)$ & $53(94.6)$ & $51(83.6)$ & \\
\hline Number of children, mean (SD) & $2.16(1.117)$ & & & & & \\
\hline $\begin{array}{l}\text { Number of years living alone (years), } \\
\text { mean (SD) }\end{array}$ & $0.90(3.491)$ & $0.69(3.204)$ & $1.55(4.910)$ & $0.73(3.419)$ & $0.87(2.699)$ & $0.62(1.146)^{b}$ \\
\hline Lives with children, n (\%) & & & & & & $1.146^{\mathrm{b}}$ \\
\hline Yes & $221(92.1)$ & $75(92.6)$ & $37(88.1)$ & $52(92.9)$ & $57(93.4)$ & \\
\hline No & $19(7.9)$ & $6(7.4)$ & $5(11.9)$ & $4(7.1)$ & $4(6.6)$ & \\
\hline Type of occupation, n (\%) & & & & & & 10.05 \\
\hline Unskilled & $76(31.7)$ & $20(24.7)$ & $16(38.1)$ & $14(25.0)$ & $26(42.6)$ & \\
\hline Semiskilled or skilled & $87(36.3)$ & $32(39.5)$ & $12(28.6)$ & $20(35.7)$ & $23(37.7)$ & \\
\hline Professional/senior managers & $77(32.1)$ & $29(35.8)$ & $14(33.3)$ & $22(39.3)$ & $12(19.7)$ & \\
\hline Retirement status, n (\%) & & & & & & $9.40^{*}$ \\
\hline Retired & $118(49.2)$ & $32(39.5)$ & $27(64.3)$ & $24(42.9)$ & $35(57.4)$ & \\
\hline
\end{tabular}




\begin{tabular}{|c|c|c|c|c|c|c|}
\hline \multirow[t]{2}{*}{ Characteristic } & \multirow[b]{2}{*}{$\begin{array}{l}\text { Full sample } \\
(\mathrm{N}=240)\end{array}$} & \multicolumn{5}{|c|}{ Preference of robot or pet as a companion } \\
\hline & & $\begin{array}{l}\text { Both are highly } \\
\text { acceptable }^{\mathrm{a}} \\
(\mathrm{n}=81,33.8 \%)\end{array}$ & $\begin{array}{l}\text { Prefer robot } \\
(\mathrm{n}=42,17.5 \%)\end{array}$ & $\begin{array}{l}\text { Prefer pet } \\
(\mathrm{n}=56,23.3 \%)\end{array}$ & $\begin{array}{l}\text { Neither is accept- } \\
\text { able }(\mathrm{n}=61,25.4 \%)\end{array}$ & $\begin{array}{l}\text { Verification } \\
\text { value }\left(F / \chi^{2}\right)\end{array}$ \\
\hline $\begin{array}{l}\text { Self-rated health ( } 1 \text { to } 5 \text { points), mean } \\
\text { (SD) }\end{array}$ & $3.53(0.731)$ & $3.58(0.756)$ & $3.50(0.672)$ & $3.43(0.828)$ & $3.59(0.642)$ & 0.644 \\
\hline $\begin{array}{l}\text { Self-rated financial status ( } 1 \text { to } 5 \text { points), } \\
\text { mean (SD) }\end{array}$ & $3.83(0.062)$ & $3.88(0.509)$ & $3.81(0.594)$ & $3.75(0.745)$ & $3.85(0.654)$ & 0.501 \\
\hline Has experience using robots, $n(\%)$ & & & & & & 3.16 \\
\hline Yes & $43(17.9)$ & $18(22.2)$ & $7(16.7)$ & $6(10.7)$ & $12(19.7)$ & \\
\hline No & $197(82.1)$ & $63(77.8)$ & $35(83.3)$ & $50(89.3)$ & $49(80.3)$ & \\
\hline $\begin{array}{l}\text { Has experience using the internet, } n \\
(\%)\end{array}$ & & & & & & 7.80 \\
\hline Yes & $196(81.7)$ & $65(80.2)$ & $30(71.4)$ & $52(92.9)$ & $49(80.3)$ & \\
\hline No & $44(18.3)$ & $16(19.8)$ & $12(28.6)$ & $4(7.1)$ & $12(19.7)$ & \\
\hline Experience using apps, $\mathrm{n}(\%)$ & & & & & & 2.51 \\
\hline $\begin{array}{l}\text { No experience with using apps/not } \\
\text { able to download }\end{array}$ & $56(23.3)$ & $20(35.7)$ & $13(23.2)$ & $12(21.4)$ & $11(19.6)$ & \\
\hline Can download and use apps & $184(76.7)$ & $61(75.3)$ & $29(69.0)$ & $44(78.6)$ & $50(82.0)$ & \\
\hline Has experience keeping pets, n (\%) & & & & & & $20.55^{* * *}$ \\
\hline Yes & $152(63.3)$ & $63(77.8)$ & $18(42.9)$ & $40(71.4)$ & $31(50.8)$ & \\
\hline No & $88(36.7)$ & $18(22.2)$ & $24(57.1)$ & $16(28.6)$ & $30(49.2)$ & \\
\hline $\begin{array}{l}\text { Animal-assisted therapy experience, } \\
\text { n (\%) }\end{array}$ & & & & & & $1.806^{\mathrm{b}}$ \\
\hline Has no animal care experience & $226(94.2)$ & $76(93.8)$ & $40(95.2)$ & $51(91.1)$ & $59(96.7)$ & \\
\hline Has animal care experience & $14(5.8)$ & $5(6.2)$ & $2(4.8)$ & $5(8.9)$ & $2(3.3)$ & \\
\hline \multicolumn{7}{|l|}{ IPIP-15 ${ }^{\mathrm{c}}>$ score, mean (SD) } \\
\hline Extroversion & $11.51(2.626)$ & $11.69(2.391)$ & $11.55(2.487)$ & $11.50(2.683)$ & $11.25(2.987)$ & 0.335 \\
\hline Friendliness & $11.78(2.141)$ & $11.77(2.260)$ & $11.76(2.034)$ & $12.02(2.244)$ & $11.59(1.978)$ & 0.390 \\
\hline Rigorousness & $11.90(2.405)$ & $11.57(2.617)$ & $12.19(2.287)$ & $12.29(2.078)$ & $11.80(2.455)$ & 1.235 \\
\hline Emotional stability & $11.28(2.746)$ & $10.91(2.651)$ & $11.71(3.263)$ & $11.34(2.345)$ & $11.41(2.831)$ & 0.884 \\
\hline Intelligence/imagination & $9.72(2.604)$ & $9.81(2.393)$ & $9.43(2.881)$ & $10.09(2.678)$ & $9.44(2.617)$ & 0.815 \\
\hline CES-D ${ }^{\mathrm{d}}$ score, mean (SD) & $5.93(5.330)$ & $6.07(5.422)$ & $6.10(5.938)$ & $5.79(5.098)$ & $5.74(5.092)$ & 0.072 \\
\hline Social participation, mean (SD) & $2.25(2.124)$ & $2.14(2.223)$ & $2.81(2.211)$ & $2.05(2.211)$ & $2.18(1.812)$ & 1.234 \\
\hline Leisure activities, mean (SD) & $7.85(2.147)$ & $8.01(2.009)$ & $7.93(2.005)$ & $7.75(2.250)$ & $7.69(2.349)$ & 0.325 \\
\hline Social support, mean (SD) & $24.88(4.462)$ & $24.67(4.693)$ & $24.88(4.743)$ & $25.05(4.020)$ & $25.00(4.431)$ & 0.104 \\
\hline eHealth Literacy Scale score, mean (SD) & $21.65(7.773)$ & $22.04(7.825)$ & $21.36(8.316)$ & $23.43(6.494)$ & $19.69(8.123)$ & 2.400 \\
\hline \multicolumn{7}{|l|}{$\begin{array}{l}\text { Acceptability }{ }^{\mathrm{a}} \text { (0 to } 10 \text { points), mean } \\
\text { (SD) }\end{array}$} \\
\hline Robot & $5.69(3.142)$ & & & & & \\
\hline Pet & $4.72(3.564)$ & & & & & \\
\hline
\end{tabular}

\footnotetext{
${ }^{\mathrm{a}}$ Acceptability was deemed to be high or low if it was higher or lower, respectively, than the average points of acceptability.

${ }^{b}$ Because the number of people who had few expectations was less than 5, the test was conducted using Fisher exact test, and the results showed no significant differences.

${ }^{\mathrm{C}}$ IPIP-15: 15-item International Personality Item Pool big 5 personality scale.

${ }^{\mathrm{d}}$ CES-D: Center for Epidemiologic Studies Depression Scale.

$* P<.05 ; * * P<.01$; and $* * * P<.001$.
} 


\section{Factors Associated With Intention to Use a Robot or Pet as Their Companion Object in Later Life}

The variables related to acceptance of robots and pets were divided into 4 groups: both robots and pets were highly acceptable $(\mathrm{HH})$, preferred a robot (HL), preferred a pet (LH), and neither robots nor pets were acceptable (LL). The level of acceptability was deemed to be high if it was higher than average and was deemed to be low if it was lower than the average. As Table 1 shows, 33.8\% (81/240) of the subjects reported both robots and pets to be acceptable (HH), 17.5\% (42/240) preferred a robot (HL), $23.3 \%(56 / 240)$ preferred a pet (LH), and $25.4 \%$ $(61 / 240)$ reported neither robots nor pets to be acceptable (LL). The results of the study showed that retirement status $\left(\chi_{3}^{2}=9.40\right.$, $P=.024)$, experience with keeping pets $\left(\chi_{3}^{2}=20.55, P=.000\right)$, and the number of comorbidities $\left(F_{3,236}=4.43, P=.005\right)$ were all significantly associated with the 4 acceptance groups. However, none of the psychological measures, including personality traits, CES-D score, and social participation, were associated with the preference for robots or pets as their companion.

Results of the multinomial logistic regression analysis used to analyze the variables in terms of their predictive power on the
4 groups of robot/pet acceptability among the middle-aged and older adults is presented in Table 2. The results showed that those with more comorbidities were 1.688 times more likely to fall into the HL group than into the LL group $(P=.048)$; those who could download and use an app were 0.170 times more likely to fall into the HL group than the LL group as compared with those who had not used or downloaded apps $(P=.022)$. Those who could download and use apps were 0.159 times more likely to fall into the HL group than into the LL group as compared with those who had not used or downloaded apps $(P=.012)$. Those with experience with keeping pets were 3.527 times more likely to fall into the $\mathrm{HH}$ group than into the LL group as compared with those who had no experience with keeping pets $(P=.002)$. Those who had experience with keeping pets were 2.498 times more likely to fall into the LH group than into the LL group as compared with those with no experience in keeping pets $(P=.034)$. Those with a higher score on eHEALS were 1.084 times more likely to fall into the $\mathrm{HH}$ group than into the LL group $(P=.039)$. Those with higher scores on eHEALS were 1.139 times more likely to fall into the HL group than into the LL group $(P=.005)$. Finally, those with higher scores on eHEALS were 1.100 times more likely to fall into the LH group than into the LL group $(P=.020)$.

Table 2. Multinomial logistic regression analysis of the degree of acceptance of robots and pets by middle-aged and older adults $(\mathrm{N}=240) .{ }^{\mathrm{a}}$

\begin{tabular}{|c|c|c|c|}
\hline \multirow[t]{2}{*}{ Characteristic } & \multicolumn{3}{|c|}{ Preference of robot or pet as a companion } \\
\hline & $\begin{array}{l}\text { Both robots and pets } \\
\text { are highly acceptable } \\
(n=81,33.8 \%[O R])\end{array}$ & $\begin{array}{l}\text { Prefer robots }(n=42, \\
17.5 \%[O R])\end{array}$ & $\begin{array}{l}\text { Prefer pets }(\mathrm{n}=56, \\
23.3 \%[\mathrm{OR}])\end{array}$ \\
\hline \multicolumn{4}{|l|}{ Age, years (reference: $\geq 75$ years old) } \\
\hline $45-54$ & 1.392 & 0.982 & 1.849 \\
\hline $55-64$ & 0.896 & 1.953 & 1.649 \\
\hline $65-74$ & 1.066 & 2.234 & 1.129 \\
\hline Number of comorbidities & 0.877 & $1.688^{*}$ & 1.348 \\
\hline Lives alone & 0.484 & 0.664 & 0.275 \\
\hline Male gender & 0.863 & 1.173 & 1.646 \\
\hline \multicolumn{4}{|l|}{ Education level (reference: above university) } \\
\hline Below primary school & 0.939 & 0.645 & 1.593 \\
\hline Secondary school/senior high school (higher vocational school) & 0.759 & 0.370 & 1.080 \\
\hline Retired & 0.555 & 1.015 & 0.771 \\
\hline Has experience using robots & 0.933 & 0.734 & 0.358 \\
\hline Has experience using the internet & 0.471 & 0.368 & 3.350 \\
\hline Can download and use apps & 0.271 & $0.170^{*}$ & $0.159 *$ \\
\hline Has experience with keeping pets & $3.527 * *$ & 0.784 & $2.498 *$ \\
\hline Social support score & 0.969 & 0.953 & 0.977 \\
\hline eHealth Literacy Scale score & $1.084^{*}$ & $1.139 * *$ & $1.100^{*}$ \\
\hline
\end{tabular}

${ }^{\mathrm{a}}$ Contrast group: neither robots nor pets are acceptable $(\mathrm{n}=61 ; 25.4 \%)$.

$* P<.05 ; * * P<.01 ;$ and $* * * P<.001$. 


\section{Subjects' Preferences for Companionship Robot Functions}

This section discusses the participants' preferences for the functions of the companionship robot as their companion object in later life. The subjects filled out questionnaires regarding their preferences or needs for functions of the companionship robot. The functions of the companionship robot included (1) family services, (2) health status monitoring, (3) safety monitoring, (4) skill and recreation-type functions (eg, juggling, dancing, singing, storytelling, news reporting, joke telling, the ability to make various expressions), and (5) interactive functions (eg, chatting, providing child-like dialogue).

The results of the study showed that the functions of the companionship robot that the subjects most desired were the skill and recreation-type functions $(211 / 240,87.9 \%)$, followed by family services $(185 / 240,77.1 \%)$, interactive functions (160/240, 66.7\%), health status monitoring (147/240, 61.3\%), and safety monitoring $(144 / 240,60.0 \%)$, as shown in Table 3. By analyzing the correlation between the sociodemographic characteristics and the function selection for the companionship robot, it was found that in addition to skill and recreation-type functions $(60 / 68,88.2 \%)$ and family services $(50 / 68,73.5 \%)$, male subjects desired health status monitoring functions $(46 / 68$, $67.6 \%$ ) of the companionship robot more than its interactive functions $(44 / 68,64.7 \%)$. Female subjects desired the safety monitoring functions $(103 / 172,59.9 \%)$ of the companionship robot more than its health status monitoring functions (101/172, $58.7 \%$ ). Among these, although the differences were not statistically significant, the middle-aged and older female subjects still preferred family service-type robots and interactive function-type robots more than the male subjects.

Table 3. Analysis of the preference of middle-aged and older adults for the companionship robot functions (N=240).

\begin{tabular}{|c|c|c|c|c|c|}
\hline \multirow[t]{2}{*}{ Characteristic } & \multicolumn{5}{|l|}{ Robot functions } \\
\hline & $\begin{array}{l}\text { Skill and recreation- } \\
\text { type functions }\end{array}$ & Family services & $\begin{array}{l}\text { Interactive func- } \\
\text { tions }\end{array}$ & $\begin{array}{l}\text { Health status monitor- } \\
\text { ing }\end{array}$ & Safety monitoring \\
\hline Full sample, n (\%) & $211(87.9)$ & $185(77.1)$ & $160(66.7)$ & $147(61.3)$ & $144(60.0)$ \\
\hline \multicolumn{6}{|l|}{ Gender } \\
\hline Male (n=68), n (\%) & $60(88.2)$ & $50(73.5)$ & $44(64.7)$ & $46(67.6)$ & $41(60.3)$ \\
\hline Female $(\mathrm{n}=172), \mathrm{n}(\%)$ & $151(87.8)$ & $135(78.5)$ & $116(67.4)$ & $101(58.7)$ & $103(59.9)$ \\
\hline$\chi^{2}$ & 0.009 & 0.678 & 0.164 & 1.636 & 0.003 \\
\hline \multicolumn{6}{|l|}{ Age } \\
\hline $45-54$ years $(\mathrm{n}=85), \mathrm{n}(\%)$ & $73(85.9)$ & $74(87.1)$ & $59(69.4)$ & $61(71.8)$ & $60(70.6)$ \\
\hline $55-64$ years $(\mathrm{n}=73), \mathrm{n}(\%)$ & $66(90.4)$ & $60(82.2)$ & $46(63.0)$ & $46(63.0)$ & $43(58.9)$ \\
\hline$\geq 65$ years $(n=82)$ & $72(87.8)$ & $51(62.2)$ & $55(67.1)$ & $40(48.8)$ & $41(50.0)$ \\
\hline$\chi^{2}$ & 0.760 & $16.156^{* * *}$ & 0.733 & $9.427 * *$ & $7.424 *$ \\
\hline \multicolumn{6}{|l|}{ Residential status } \\
\hline Living alone $(\mathrm{n}=25), \mathrm{n}(\%)$ & $23(92.0)$ & $15(60.0)$ & $16(64.0)$ & $15(60.0)$ & $11(44.0)$ \\
\hline Not living alone $(\mathrm{n}=215), \mathrm{n}(\%)$ & $188(87.4)$ & $170(79.1)$ & $144(67.0)$ & $132(61.4)$ & $133(61.9)$ \\
\hline$\chi^{2}$ & 0.438 & $4.610^{*}$ & 0.089 & 0.018 & 2.977 \\
\hline \multicolumn{6}{|l|}{ Marital status } \\
\hline Have a partner $(\mathrm{n}=170), \mathrm{n}(\%)$ & $153(90.0)$ & $134(78.8)$ & $113(66.5)$ & $111(65.3)$ & 107 (62.9) \\
\hline Have no partner $(\mathrm{n}=70), \mathrm{n}(\%)$ & $58(82.9)$ & $51(72.9)$ & $47(67.1)$ & $36(51.4)$ & $37(52.9)$ \\
\hline$\chi^{2}$ & 2.381 & 0.999 & 0.010 & $4.016^{*}$ & 2.101 \\
\hline
\end{tabular}

$* P<.05 ; * * P<.01 ;$ and $* * * P<.001$.

According to the results of the analysis on residential status and preferences for functions of the companionship robot, $64 \%$ $(16 / 25)$ of the people living alone had a greater preference and demand for interactive functions, which took second place among those living alone in terms of the desired functions of the companionship robot. Among these subjects, whether or not they lived alone was significantly related to the preference for family service (ie, housework) functions $(P=.032)$. The results for choosing skill and recreation-type functions for the companionship robot by those living alone were not statistically significant, but there was still a tendency toward choosing this type of robot.

The results of the analysis on the marital status and the preference for the companionship robot functions showed that for subjects who had no partner, the level of preference and demand for safety monitoring functions was higher than for health status monitoring functions, and having a partner was significantly related to the choice of health status monitoring functions $(P=.045)$. 
The subjects were divided into 3 age groups: 45 to 54 years, 55 to 64 years, and $\geq 65$ years. By analyzing the choices made by the elderly in each age group for the functions of the companionship robot, it was found that the subjects ranging in age from 45 to 54 years mainly preferred the family service-type robot followed by the skill and recreation-type robot. However, subjects who were aged 55 to 64 years and over 65 years all chose the skill and recreation-type robot, including the functions of juggling, dancing, singing, storytelling, news reporting, joke telling, and the ability to make various expressions, followed by the family service-type robot. The different ages were significantly related to the choice of family service $(P<.001)$, health status monitoring $(P=.009)$, and safety monitoring $(P=.026)$ functions of the companionship robot.

\section{Subjects' Preferences for the Appearance of the Companionship Robot}

This section discusses the preferences of the middle-aged and older adults for the appearance of the companionship robot as their companion object in later life. The subjects filled out a questionnaire according to their preferences or requirements for the appearance of the companionship robot, which included animal, infant, adult, and nonbiological or other form.
It was found that the appearance of the companionship robot that the subjects most desired/preferred was one resembling an animal $(94 / 240,39.2 \%)$, followed by one resembling an adult (72/240,30.0\%), an infant (43/240, 17.9\%), and a nonbiological or other form $(21 / 240,8.9 \%)$. The results are shown in Table 4. The analysis of the correlation between the sociodemographic characteristics and the choice of the appearance of the companionship robot showed that male subjects preferred a companionship robot that resembled an adult $(29 / 68,42.6 \%)$, followed by an animal-like appearance $(23 / 68,33.8 \%)$, where gender was found to be significantly related to the preference for the companionship robot to look like a human adult $(P=.007)$. The correlations between residential status and marital status with choice of robot appearance did not reach statistical significance, but living alone and with a partner had the same ranking as the full sample in terms of this preference. Regardless of age, the appearance of animals was the most popular choice of robot appearance. The second most preferred robot appearance was that of a human adult among subjects who were aged 45 to 54 years old and those aged 55 to 64 years; subjects who were $\geq 65$ years preferred the infant- and adult-like appearances equally.

Table 4. Analysis of the preference of the middle-aged and older adults for the appearance of the companionship robot $(\mathrm{N}=240)$.

\begin{tabular}{|c|c|c|c|c|}
\hline \multirow[t]{2}{*}{ Characteristic } & \multicolumn{4}{|c|}{ Preferred appearance of companionship robot } \\
\hline & Animal & Adult & Infant & Other \\
\hline Full sample, n (\%) & $94(39.2)$ & $72(30.0)$ & $43(17.9)$ & $21(8.9)$ \\
\hline \multicolumn{5}{|l|}{ Gender } \\
\hline Male $(\mathrm{n}=68), \mathrm{n}(\%)$ & $23(33.8)$ & $29(42.6)$ & $7(10.3)$ & $4(5.9)$ \\
\hline Female $(\mathrm{n}=172), \mathrm{n}(\%)$ & $71(41.3)$ & $43(25.0)$ & $36(20.9)$ & $17(9.9)$ \\
\hline$\chi^{2}$ & 1.137 & $7.227 * *$ & 3.749 & 0.977 \\
\hline \multicolumn{5}{|l|}{ Age } \\
\hline $45-54$ years $(\mathrm{n}=85), \mathrm{n}(\%)$ & $36(42.4)$ & $13(15.3)$ & $28(32.9)$ & $8(9.4)$ \\
\hline $55-64$ years $(n=73), n(\%)$ & $29(39.7)$ & $12(16.4)$ & $26(35.6)$ & $7(9.6)$ \\
\hline$\geq 65$ years $(n=82), n(\%)$ & $29(35.4)$ & $18(22.0)$ & $18(22.0)$ & $6(7.3)$ \\
\hline$\chi^{2}$ & 0.869 & 3.976 & 1.414 & 0.322 \\
\hline \multicolumn{5}{|l|}{ Residential status } \\
\hline Living alone $(\mathrm{n}=25)$ & $73(42.9)$ & $51(30.0)$ & $27(15.9)$ & $16(9.4)$ \\
\hline Not living alone $(\mathrm{n}=215)$ & $21(30.0)$ & $21(30.0)$ & $16(22.9)$ & $5(7.1)$ \\
\hline$\chi^{2}$ & 3.485 & 0.000 & 1.640 & 0.320 \\
\hline \multicolumn{5}{|l|}{ Marital status } \\
\hline Have a partner $(\mathrm{n}=170)$ & $12(48.0)$ & $8(32.0)$ & $4(16.0)$ & $1(4.0)$ \\
\hline Have no partner $(\mathrm{n}=70)$ & $82(38.1)$ & $64(29.8)$ & $39(18.1)$ & $20(9.3)$ \\
\hline$\chi^{2}$ & 0.914 & 0.053 & 0.070 & 0.789 \\
\hline
\end{tabular}

$* * P<.01$ 


\section{Discussion}

\section{Principal Findings}

The main purpose of this study was to discuss the level of acceptance of middle-aged and older adults toward a robot or pet as their companion object in later life; to understand the correlation between sociodemographic variables, physical health, mental health, behavioral factors, and preferences for either a robot or pet as a companion object in later life; and to further analyze the needs and preferences of the subjects for the functions and appearance of a companionship robot. The results of the community survey showed that the level of acceptance of subjects in the community toward a pet as their companion object in later life was significantly correlated with their age, with a higher age being associated with a lower average score for acceptance of a pet. Acceptance of pets was significantly correlated with education level, type of occupation, retirement status, number of comorbidities, past experience with keeping pets, an extroverted personality, an intellectual/imaginary personality, and eHealth literacy. In terms of the acceptance toward robots, there were no significant differences in the level of acceptance based on age group. The level of acceptance toward robots was only significantly related to the type of dwelling the subject lived in. No correlation between the acceptance toward robots and other sociodemographic variables, or physical health, mental health, or behavioral factors was observed in this study.

According to the acceptability score, the level of acceptance of the middle-aged and older adults for choosing between a robot or pet as their companion object in later life was divided into 4 groups: both are highly accepted (HH), preferred a robot (HL), preferred a pet (LH), and neither was acceptable (LL). When the average acceptability score was used as the grouping standard, there were significant differences in terms of retirement status, number of comorbidities, and past experience with keeping pets among each group of subjects. The results of the multinomial logistic regression analysis on the key variables showed that the number of comorbidities, experience with keeping pets, experience with using apps, and eHealth literacy had significant predictive power for the level of acceptability among all of the groups; however, gender, intergenerational differences, education level, whether or not subjects lived alone, social support, and past experience with keeping pets had no significant impact on the level of acceptability among the various groups.

According to the theory of planned behavior, attitude, subjective norms, and perceived behavioral control are the 3 factors that determine behavior [28]. In the research, although the reasons for the significant variables were not further explored, we can infer that personality, education level, type of occupation, and past experience with keeping pets, which can affect the experience of life, might be related to personal attitude. The type of dwelling in which a person resides may affect their preference for robots or pets. It may be related to subjective norms; after all, sometimes living conditions such as neighbors or house size might restrict one from keeping pets. On the other hand, age (related to one's functional ability to keep pets), retirement status (ie, how much leisure time someone has), number of comorbidities, experience with using apps, and eHealth literacy might be related to perceived behavioral control. Overall, the results showed that preferences for robots and pets among middle-aged and older adults conformed to the theory of planned behavior.

By analyzing the needs and preferences of middle-aged and older adults for the companionship robot, it was found that these individuals desired/favored robot skills such as juggling, dancing, singing, storytelling, news reporting, joke telling, or the ability to make various expressions, followed by family service, interactive, health status monitoring, and safety monitoring functions. In terms of the appearance of the companionship robot, the middle-aged and older adults preferred the robot to look like an animal, followed by it having an adult-like appearance, infant-like appearance, and nonbiological or other appearance, in that order. By further analyzing the impact of sociodemographic characteristics on the preferences for the companionship robot, it was found that whether the subjects lived alone or not significantly affected the choice of the family service function of the robot, and whether there was a partner or not also significantly affected whether the subjects chose the health status monitoring function of the robot. Male subjects showed a greater preference for an adult-like appearance in the robot than did female subjects, and the difference was statistically significant. Female subjects preferred an animal-like appearance to the robot over an adult-like appearance.

\section{Comparison With Prior Work}

Most studies on the appearance of robots have pointed out that elderly individuals prefer less human-looking robots such as pet-like robots, which have been widely used in the past to care for the elderly and are highly accepted by them $[12,13,45]$. Studies in Japan showed that the robotic seal pet PARO, because its seal-like appearance was unfamiliar to people, did not lead to an unreal sense of interaction with a fake animal and was easily accepted by the elderly [46]. A study discussing robots in the daily lives of the elderly in Taiwan pointed out that older adults were more likely to accept robot pets of traditional pet animals, such as cats or dogs, because the elderly associated the robots with animals they were familiar with, and those who had no experience with keeping pets wanted pet-like robots as pets [47]. A study discussing the needs of the elderly for the companionship robot when they entered the "empty-nest" period indicated that the appearance of a future companionship robot needed to be based on human life experiences. For example, the Hug is a robot that allows the elderly to maintain social and affective interactions by communicating closely with their families. It was designed to look like a human offering a hug and has specific types of communication functions [48]. The SenseChair is a robot that was designed to look like a "chair" that the elderly are familiar with in their daily life [49]. In terms of the robot's functions, the main purpose of using a home-based robot was to obtain the "home service" function, following by providing assistance to people with mobility disabilities, home security management, remote monitoring, emotional pacification, and so on. The study also pointed out that companionship robots with more social functions are more likely to elicit expressions and responses from the elderly and 
to promote the participation of the elderly in social interactions and enhance the quality of their interactions $[19,50]$.

\section{Limitations and Future Work}

There were some limitations to this study. First, the research tool was self-reported, and the subjects' understanding of the questions in the questionnaire and their personal perception of their own situation all affected their answers. The subjects' answers might have been affected by extrinsic factors beyond their control such as mood and social expectations, so the results of the inventory might have been different from their actual situation, resulting in measurement errors in the results of the study. Second, the sampling sites for the study were gathering places for the elderly, such as community care strongholds and community centers, and at activities intended to respect the elderly and as part of Mother's Day events. The subjects were middle-aged and older adults who were more active and had the intention and ability to go out, so the results of the study are limited in terms of extrapolation. Third, the sample size and representativeness of the subjects were not as good as probability sampling, which affected any inferences that could be made based on the results, although the study areas covered the northern, central, and southern parts of Taiwan to increase the robustness of the results of the study. Fourth, this research is the first attempt at understanding companionship preferences toward pets and robots among the elderly in the community in Taiwan. Therefore, cultural factors were not considered. Similarly, because there have been few studies of this topic abroad [29], it is difficult to know whether there are similarities or differences between cultures, which is an expectant direction for future work.

In spite of these limitations, this study is a rare survey of the perceptions of elderly individuals living in the community toward companionship robots. The subjects in this study were aged 45 to 94 years and included active middle-aged and older adults living in the community in the northern, central, and southern parts of Taiwan. It is the only study in Taiwan to compare pets and robots from the point of view of choosing them as a companion object. From the results of the study, we can preliminarily understand the current situation and preferences of the needs for companionship in middle-aged and older adults living in the community. In addition to contributing to the literature, middle-aged and older adults at home can find a suitable companion object in later life based on their sociodemographic characteristics. First-line community practitioners can also design care projects for middle-aged and older adults living with different needs and backgrounds and provide a future implementation plan for the welfare system, as well as provide empirical evidence for policy promotion and the development of science- and technology-related industrial products.

\section{Conclusion}

The key findings of this study are as follows. First, variables such as age, education level, type of dwelling, occupation, retirement status, number of comorbidities, experience with keeping pets, experience with using apps, and eHealth literacy significantly affected the degree of acceptance of a robot or pet as a companion object in later life. Community practitioners working with middle-aged and older adults could plan curricula according to the different backgrounds and characteristics of the population of interest to develop care projects for middle-aged and older adults based on their different needs and backgrounds and help them to select appropriate companion objects in later life. Second, the study found that eHealth literacy significantly affected the degree of acceptance of robots and pets in the middle-aged and older adults as well as the type of functions desired in a companion robot. Those with higher eHealth literacy scores were more likely to respond that both robots and pets were acceptable as companion objects. This indicates that those with better eHealth literacy are more likely to choose a robot or pet as their companion object in later life and that eHealth literacy is significantly associated with age. First-line staff or policy makers in relevant fields can conduct eHealth literacy promotion courses for middle-aged and older adults in order to facilitate the implementation of relevant plans. Third, in terms of the development of companionship robot products, middle-aged and older women generally preferred animal-like robots as companion objects in later life, while men preferred an adult human-like robot. In terms of functions, middle-aged and older adults in the community are more likely to need a companionship robot that has functions including dancing, singing, storytelling, or news reporting. Whether or not they live alone or with a partner also affects their preferred robot functions, so technology-related industries should consider designing products to suit the needs of different target groups. It would be useful to increase the number of study samples or select specific groups to carry out intensive studies. Heterogeneous populations in residential institutions or extension of the sampling sites could make the results more generalizable. In addition, qualitative study methods such as in-depth interviews would help lead to an understanding of the needs of middle-aged and older adults in terms of a companion in later life. Study methods attaching equal importance to quality and quantity in the future could potentially better reflect the current needs of middle-aged and older adults.

\section{Conflicts of Interest}

None declared.

\section{Multimedia Appendix 1}

Different types of robots. 


\section{Multimedia Appendix 2}

Questionnaires.

[DOCX File, 50 KB-Multimedia Appendix 2]

\section{References}

1. Khosravi P, Ghapanchi AH. Investigating the effectiveness of technologies applied to assist seniors: A systematic literature review. Int J Med Inform 2016 Jan;85(1):17-26. [doi: 10.1016/j.ijmedinf.2015.05.014] [Medline: 26216463]

2. Chiu C, Liu C. Understanding Older Adult's Technology Adoption and Withdrawal for Elderly Care and Education: Mixed Method Analysis from National Survey. J Med Internet Res 2017 Nov 03;19(11):e374 [FREE Full text] [doi: 10.2196/jmir.7401] [Medline: 29101093]

3. Chiu C, Hu Y, Lin D, Chang F, Chang C, Lai C. The attitudes, impact, and learning needs of older adults using apps on touchscreen mobile devices: Results from a pilot study. Comput Hum Behav 2016 Oct;63:189-197. [doi: 10.1016/j.chb.2016.05.020]

4. Fischer SH, David D, Crotty BH, Dierks M, Safran C. Acceptance and use of health information technology by community-dwelling elders. Int J Med Inform 2014 Sep;83(9):624-635 [FREE Full text] [doi: 10.1016/j.ijmedinf.2014.06.005] [Medline: 24996581]

5. Law M, Sutherland C, Ahn HS, MacDonald BA, Peri K, Johanson DL, et al. Developing assistive robots for people with mild cognitive impairment and mild dementia: a qualitative study with older adults and experts in aged care. BMJ Open 2019 Sep 24;9(9):e031937 [FREE Full text] [doi: 10.1136/bmjopen-2019-031937] [Medline: 31551392]

6. Dünnebeil S, Sunyaev A, Blohm I, Leimeister JM, Krcmar H. Determinants of physicians' technology acceptance for e-health in ambulatory care. Int J Med Inform 2012 Nov;81(11):746-760. [doi: 10.1016/j.ijmedinf.2012.02.002] [Medline: 22397989]

7. Yeh MI. Robots and application in healthcare. Leadership Nursing 2016;17(4):3-12. [doi: $10.29494 / L N .201612$ 17(4).0001]

8. Robinson H, MacDonald B, Broadbent E. The Role of Healthcare Robots for Older People at Home: A Review. Int J of Soc Robotics 2014 Jul 3;6(4):575-591. [doi: 10.1007/s12369-014-0242-2]

9. Broadbent E, Tamagawa R, Patience A, Knock B, Kerse N, Day K, et al. Attitudes towards health-care robots in a retirement village. Australas J Ageing 2012 Jun;31(2):115-120. [doi: 10.1111/j.1741-6612.2011.00551.x] [Medline: 22676171]

10. Broekens J, Heerink M, Rosendal H. Assistive social robots in elderly care: a review. Gerontechnology 2009;8(2):94-103. [doi: $10.4017 /$ gt.2009.08.02.002.00]

11. Arras K, Cerqui D. Do we want to share our lives and bodies with robots? A 2000 people survey. Tech Rep 2005:13-19.

12. Ejdys J, Halicka K. Sustainable Adaptation of New Technology-The Case of Humanoids Used for the Care of Older Adults. Sustainability 2018 Oct 18;10(10):3770. [doi: 10.3390/su10103770]

13. Banks MR, Willoughby LM, Banks WA. Animal-assisted therapy and loneliness in nursing homes: use of robotic versus living dogs. J Am Med Dir Assoc 2008 Mar;9(3):173-177. [doi: 10.1016/j.jamda.2007.11.007] [Medline: 18294600]

14. Sheba JK, Phuc LT, Salman AA, Kumar S, Elara MR, Martínez-García E. Development of Rehabilitative Multimodal Interactive Pet Robot for Elderly Residents. Procedia Comput Sci 2018;133:401-408. [doi: 10.1016/j.procs.2018.07.049]

15. Yu R, Hui E, Lee J, Poon D, Ng A, Sit K, et al. Use of a Therapeutic, Socially Assistive Pet Robot (PARO) in Improving Mood and Stimulating Social Interaction and Communication for People With Dementia: Study Protocol for a Randomized Controlled Trial. JMIR Res Protoc 2015 May 01;4(2):e45 [FREE Full text] [doi: 10.2196/resprot.4189] [Medline: 25934173]

16. Wada K, Shibata T, Saito T, Sakamoto K, Tanie K. Psychological and social effects of one year robot assisted activity on elderly people at a health service facility for the aged. 2005 Presented at: Proceedings of the 2005 IEEE International Conference on Robotics and Automation; 2005; Barcelona, Spain. [doi: 10.1109/robot.2005.1570535]

17. Marti P, Bacigalupo M, Giusti L, Mennecozzi C, Shibata T. Socially assistive robotics in the treatment of behavioural and psychological symptoms of dementia. 2006 Presented at: The First IEEE/RAS-EMBS International Conference on Biomedical Robotics and Biomechatronics, 2006. BioRob 2006; 2006; Pisa, Italy. [doi: 10.1109/biorob.2006.1639135]

18. Huschilt J, Clune L. The use of socially assistive robots for dementia care. J Gerontol Nurs 2012 Oct;38(10):15-19. [doi: 10.3928/00989134-20120911-02] [Medline: 22998095]

19. Abdi J, Al-Hindawi A, Ng T, Vizcaychipi MP. Scoping review on the use of socially assistive robot technology in elderly care. BMJ Open 2018 Feb 12;8(2):e018815 [FREE Full text] [doi: 10.1136/bmjopen-2017-018815] [Medline: 29440212]

20. Coşar S, Fernandez-Carmona M, Agrigoroaie R, Pages J, Ferland F, Zhao F, et al. ENRICHME: Perception and Interaction of an Assistive Robot for the Elderly at Home. Int J Soc Robotics 2020 Feb 01;12(3):779-805. [doi:

10.1007/s12369-019-00614-y]

21. Shibata T, Wada K. Robot therapy: a new approach for mental healthcare of the elderly - a mini-review. Gerontology 2011;57(4):378-386 [FREE Full text] [doi: 10.1159/000319015] [Medline: 20639620]

22. Stern C. The meaningfulness of Canine-Assisted Interventions (CAIs) on the health and social care of older people residing in long term care: a systematic review. JBI Libr Syst Rev 2011;9(21):727-790. [doi: 10.11124/01938924-201109210-00001] [Medline: 27820415] 
23. Garrity TF, Stallones LF, Marx MB, Johnson TP. Pet Ownership and Attachment as Supportive Factors in the Health of the Elderly. Anthrozoös 2015 Apr 27;3(1):35-44. [doi: 10.2752/089279390787057829]

24. Chowdhury E, Nelson M, Jennings G, Wing L, Reid C. Pet ownership and survival in the elderly hypertensive population. J Hypertens 2017;35(4):769-775. [doi: 10.1097/hjh.0000000000001214]

25. Filan SL, Llewellyn-Jones RH. Animal-assisted therapy for dementia: a review of the literature. Int Psychogeriatr 2006 Apr 26;18(4):597-611. [doi: 10.1017/s1041610206003322]

26. Mordoch E, Osterreicher A, Guse L, Roger K, Thompson G. Use of social commitment robots in the care of elderly people with dementia: a literature review. Maturitas 2013 Jan;74(1):14-20. [doi: 10.1016/j.maturitas.2012.10.015] [Medline: 23177981]

27. Yeh M, Liao H, Chen S. Animal-Assisted Therapy in Taiwan. J Formos Med Assoc 2002;6(1):102-106.

28. Ajzen I. The theory of planned behavior. Organ Behav Hum Decis Process 1991 Dec;50(2):179-211. [doi: 10.1016/0749-5978(91)90020-t]

29. Thodberg K, Sørensen LU, Videbech PB, Poulsen PH, Houbak B, Damgaard V, et al. Behavioral Responses of Nursing Home Residents to Visits From a Person with a Dog, a Robot Seal or a Toy Cat. Anthrozoös 2016 Mar 08;29(1):107-121. [doi: 10.1080/08927936.2015.1089011]

30. Hu HF, Wang CH, Chang SM, Huang HC, Lai ZY, Sung HC. Preliminary Study on the Effects of Robot-Assisted Therapy on Depression and Agitated Behaviors among Older People with Dementia. VGH Nursing 2014;31(4):379-387. [doi: 10.6142/VGHN.31.4.379]

31. Hu HF, Sung HC. A Nursing Experience of Using a Robot-assisted Therapy for Behavioral and Psychological Symptoms of an Institutionalized Older Adult with Dementia. J Long-Term Care 2012;16(1):91-102. [doi: 10.6317/LTC.201204 16(1).0006]

32. Leng M, Liu P, Zhang P, Hu M, Zhou H, Li G, et al. Pet robot intervention for people with dementia: A systematic review and meta-analysis of randomized controlled trials. Psychiatry Res 2019 Jan;271:516-525. [doi:

10.1016/j.psychres.2018.12.032] [Medline: 30553098]

33. Cruz-Sandoval D, Morales-Tellez A, Sandoval EB, Favela J. A social robot as therapy facilitator in interventions to deal with dementia-related behavioral symptoms. 2020 Presented at: 2020 ACM/IEEE International Conference on Human-Robot Interaction; March 23-26, 2020; UK. [doi: 10.1145/3319502.3374840]

34. Health Promotion Administration. Long-term follow-up survey on the physical and mental social life of middle-aged and elderly people. Health Promotion Administration. 2011. URL: https://www.hpa.gov.tw/Pages/List.aspx?nodeid=108 [accessed 2018-01-15]

35. Barrera M, Sandler IN, Ramsay TB. Preliminary development of a scale of social support: Studies on college students. Am J Community Psychol 1981;9(4):435-447. [doi: 10.1007/bf00918174]

36. Luo KN. A Study on the Influence of Social Support, Personality Traits, and Personal Attributes on the Psychological Well-Being of the Elderly [master thesis]. Taipei, Taiwan: Department of Psychology, National Cheng Chi University; 2001.

37. Li SY. The Relationship of Resources loss, Social Support, Coping Style, and Psychological Well-Being among Middle-Aged and Older People in Taiwan [master thesis]. Taichung, Taiwan: Department of Psychology, Chung Shan Medical University; 2013:1-132.

38. Radloff LS. The CES-D Scale. Appl Psychol Meas 2016 Jul 26;1(3):385-401. [doi: 10.1177/014662167700100306]

39. Lee KL, Ou YL, Chen SH. The Psychometric Properties of a Short Form of the CES-D used in the Taiwan Longitudinal Study on Aging. Formosa Journal of Mental Health 2009;22(4):383-410.

40. Goldberg LR. The development of markers for the Big-Five factor structure. Psychol Assess 1992;4(1):26-42. [doi: 10.1037/1040-3590.4.1.26]

41. Zheng L, Goldberg LR, Zheng Y, Zhao Y, Tang Y, Liu L. Reliability and Concurrent Validation of the IPIP Big-Five Factor Markers in China: Consistencies in Factor Structure between Internet-Obtained Heterosexual and Homosexual Samples. Pers Individ Dif 2008 Nov 01;45(7):649-654 [FREE Full text] [doi: 10.1016/j.paid.2008.07.009] [Medline: 20383283]

42. Li RH, Chen YC. The Development of a Shortened Version of IPIP Big Five Personality Scale and the Testing of Its Measurement Invariance between Middle-Aged and Older People. Journal of Educational Research and Development 2016;12(4):87-119. [doi: 10.3966/181665042016121204004]

43. Norman CD, Skinner HA. eHEALS: The eHealth Literacy Scale. J Med Internet Res 2006 Nov 14;8(4):e27 [FREE Full text] [doi: 10.2196/jmir.8.4.e27] [Medline: 17213046$]$

44. Cheng SY, Chang FC, Li JM. eHealth Literacy and Related Factors among Junior High School Students in Taipei City. J Health Promot Health Educ 2014;41:1-24.

45. Arras K, Cerqui D. Do we want to share our lives and bodies with robots? A 2000 people survey. Tech Rep 2005:605-605.

46. Yu R, Hui E, Lee J, Poon D, Ng A, Sit K, et al. Use of a Therapeutic, Socially Assistive Pet Robot (PARO) in Improving Mood and Stimulating Social Interaction and Communication for People With Dementia: Study Protocol for a Randomized Controlled Trial. JMIR Res Protoc 2015 May 01;4(2):e45 [FREE Full text] [doi: 10.2196/resprot.4189] [Medline: 25934173]

47. Huang YC, Deng YS. Design Guidelines of Companion Robot for Elderly People [thesis]. Hsinchu, Taiwan: National Chiao Tung University; 2007. 
48. DiSalvo C, Gemperle F, Forlizzi J, Montgomery E. The hug: an exploration of robotic form for intimate communication. 2003 Presented at: The 12th IEEE International Workshop on Robot and Human Interactive Communication (ROMAN); 2003; Millbrae, CA, USA p. 403-408. [doi: 10.1109/roman.2003.1251879]

49. Forlizzi J, DiSalvo C, Zimmerman J, Mutlu B, Hurst A. The SenseChair: The lounge chair as an intelligent assistive device for elders. 2005 Presented at: The Conference on Designing for User eXperience; 2005; San Francisco, California, USA.

50. Heerink M, et al. Enjoyment intention to use and actual use of a conversational robot by elderly people. In: Proceedings of the 3rd ACM/IEEE international conference on human robot interaction. 2008 Presented at: 3rd ACM/IEEE international conference on human robot interaction; March 2008; Amsterdam, The Netherlands.

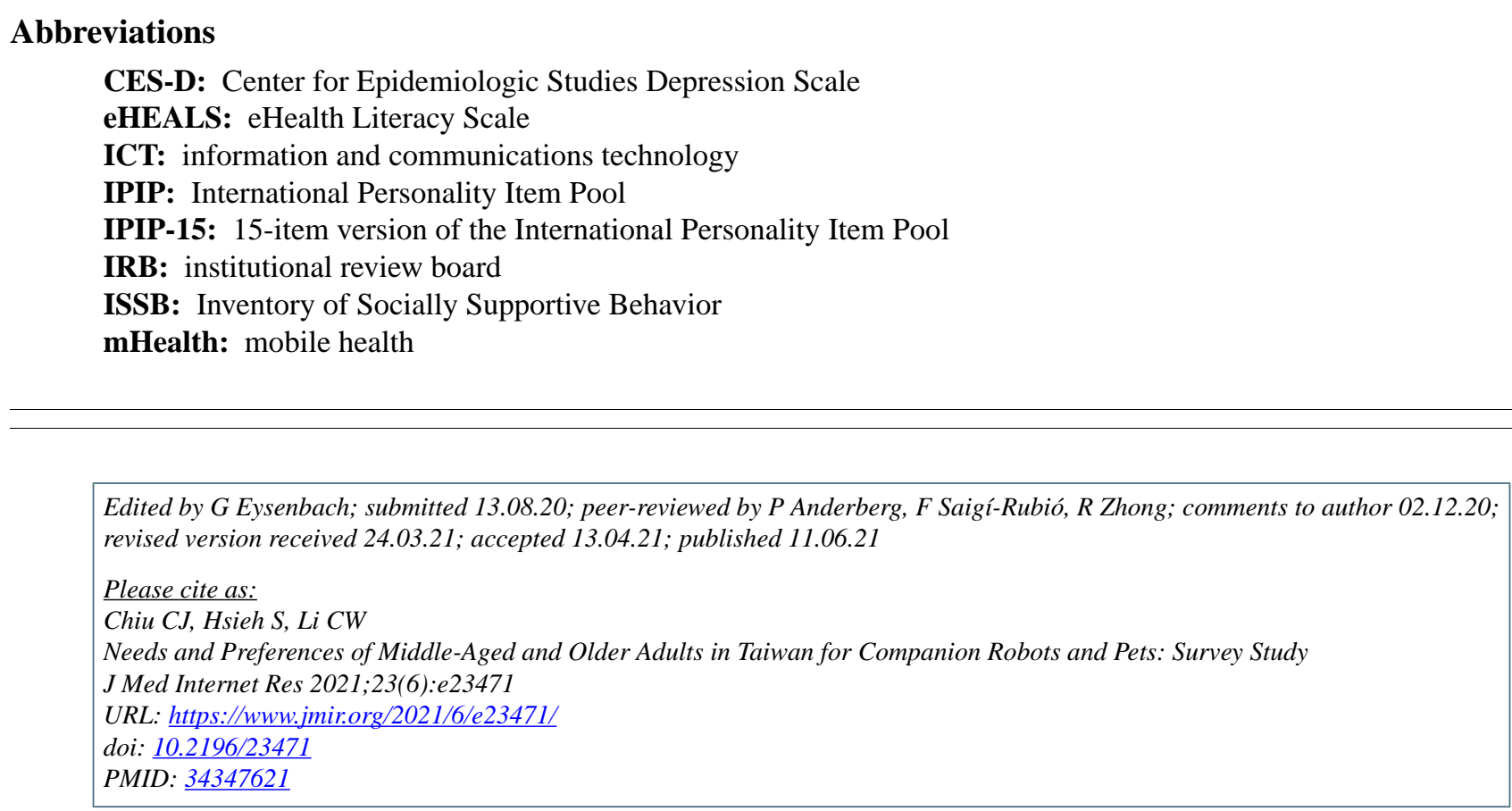

(C) Ching-Ju Chiu, Shiuan Hsieh, Chia-Wei Li. Originally published in the Journal of Medical Internet Research (https://www.jmir.org), 11.06.2021. This is an open-access article distributed under the terms of the Creative Commons Attribution License (https://creativecommons.org/licenses/by/4.0/), which permits unrestricted use, distribution, and reproduction in any medium, provided the original work, first published in the Journal of Medical Internet Research, is properly cited. The complete bibliographic information, a link to the original publication on https://www.jmir.org/, as well as this copyright and license information must be included. 